\title{
How Do We Manage HLA-B27-associated Ocular Inflammation Refractory or Intolerant to Conventional Immunomodulatory Therapy?
}

\author{
Doan Luong Hien, MD ${ }^{1,2}$; Brandon Huy Pham, BS ${ }^{1}$; Quan Dong Nguyen, MD, MS ${ }^{1}$ \\ ${ }^{1}$ Spencer Center for Vision Research, Byers Eye Institute, Stanford University, Palo Alto, California, USA \\ ${ }^{2}$ Pham Ngoc Thach University of Medicine, Saigon, Vietnam \\ ORCID: \\ Doan Luong Hien: https://orcid.org/0000-0003-0856-871X \\ Quan Dong Nguyen: https://orcid.org/0000-0002-6024-8441
}

J Ophthalmic Vis Res 2020; 15 (4): 442-445

The HLA-B27 gene is among the most studied genes in the history of medicine, and its relationship to ocular inflammation is well established. In particular, it has been known to be associated primarily with anterior chamber inflammation with clinical manifestations of nongranulomatous keratic precipitates, anterior chamber cells and flare, and in some cases, fibrin and/or hypopyon. With modern advanced imaging technologies, posterior segment involvement, including papillitis and retinal vasculitis can be detected in up to $31 \%$ of patients with HLAB27-associated uveitis. ${ }^{[1]}$ Moreover, wide-angle imaging has allowed the diagnosis of peripheral retinal vasculitis that may be missed by standard imaging modalities. ${ }^{[2,3]}$

Although the long-term visual prognosis of HLA-B27-associated acute anterior uveitis (AAU) is generally favorable, ${ }^{[4]}$ patients with HLA-B27associated AAU are approximately five times more likely to have a visual acuity of 20/200 or worse as compared to patients without HLAB27-positivity. ${ }^{[5]}$ Suboptimal visual outcomes may be complicated by steroid-induced side effects or delay in treatment of refractory cases; therefore, close monitoring with multimodality imaging and employing a stepladder approach in the management is necessary in every patient. Unfortunately, since relatively few studies have examined HLA-B27-associated AAU, and even fewer have focused on refractory cases, HLA-B27associated AAU remains a significant therapeutic challenge for uveitis specialists. In their well-written manuscript and well-designed study published in the current issue of Journal of Ophthalmic and
Vision Research (JOVR), Bajwa and colleagues ${ }^{[6]}$ contribute to the literature by discussing the utility of infliximab in managing this particularly challenging disease.

Recent prospective randomized controlled trials have shown that intraocular inflammation can be controlled in $57.1-66.7 \%$ of cases with firstline immunomodulatory therapy (IMT) agents, such as methotrexate and mycophenolate mofetil. ${ }^{[7]}$ Uveitis that involves the posterior segment may not always respond to first-line IMT and at time requires adjustment to second- or thirdline agents, including biologics or other steroidsparing agents. Infliximab and adalimumab are the two most commonly used biologic agents for noninfectious posterior uveitis (NIU). Unlike adalimumab, infliximab has not been approved by the FDA for NIU and is used off-label for ocular inflammation. Data supporting the use of infliximab in NIU stems largely from retrospective and small prospective trials. ${ }^{[8-17]}$ Infliximab can be used as first-line therapy for certain systemic diseases such as Adamantiades-Behçet disease ${ }^{[18]}$ and in cases of sight-threatening disease in the setting of moderate to severe idiopathic retinal vasculitis and optic disc inflammation, or as a third-line therapy in uveitis refractory to corticosteroids and conventional IMT. The efficacy of infliximab is fairly rapid-onset, with one study demonstrating $96 \%$ resolution of acute inflammation one day after infusion, ${ }^{[19]}$ which is quite fast as compared to adalimumab, in which the typical time to effectiveness typically ranges from 2 to 16 weeks. ${ }^{[20]}$ These findings are consistent with the study by Bajwa et $\mathrm{al}^{[6]}$ which demonstrated 
81.25\% responsiveness after three months and 87.5\% responsiveness after six months.

Some IMT agents, such as methotrexate and mycophenolate mofetil, may take 8-12 weeks before reaching maximum efficacy; adalimumab takes a median of six weeks. ${ }^{[20]}$ Therefore, three months of follow-up is inadequate to determine unresponsiveness. We typically follow our patient in the clinics for six months or more to fully assess drug efficacy and responsiveness. It is important to continue therapy during this time even if the disease is in stable condition in order to achieve long-term quiescence and remission. Adalimumab was FDA-approved for the treatment of NIU after the completion of two successful phase-3 multicenter randomized controlled trials, VISUAL I and II, that investigated the use of adalimumab strictly for intermediate, posterior, or pan-uveitis. ${ }^{[21,22]}$ No specific data regarding the percentage and subtypes of HLAB27-associated uveitis is available from the VISUAL I and II studies. It is quite interesting that many patients had refractory anterior uveitis in the Bajwa study ${ }^{[6]}$ prior to the study entry and $20.8 \%$ were considered to be unresponsive or intolerant to adalimumab therapy. It would be beneficial if Bajwa and colleagues could provide information on prior immunosuppression treatment regimens including route, time, and dosage. Moreover, no clear definition of "unresponsive inflammation" is provided. According to the study, 9.5-19\% of patients experienced a flare up while on treatment with infliximab, and one patient developed vasculitis after 3 months of treatment which remained active until 24 months. We suspect that the authors may be more in favor of infliximab than other IMT agents, having kept the patient on a similar treatment regimen.

In addition, the authors discuss antibody formation against infliximab. It would be very helpful to know whether testing for this antibody was performed as well as how many patients were on concurrent IMT (such as methotrexate or mycophenolate) to prevent or decrease the risk of antibody formation. In the Bajwa study, ${ }^{[6]}$ treatment was prematurely stopped in three patients, and one patient still had active disease at the end of 24 months. The authors can speculate or suggest what may be the next treatment option(s) for these patients.

In summary, while infliximab is a robust treatment, roughly $10-20 \%$ of patients may not show an adequate response to therapy. These patients may need augmentation with additional therapeutic approaches. Recent emerging and adopted therapies, including tocilizumab (STOP study), ${ }^{[23]}$ sarilumab (SATURN study), ${ }^{[24]}$ and sirolimus (SAVE-2 and SAKURA studies), ${ }^{[25-28]}$ have shown encouraging efficacy outcomes with a relatively favorable safety profile. Other clinical trials evaluating the safety and efficacy of filgotinib, ${ }^{[29]}$ tofacitinib, ${ }^{[30]}$ and adrenocorticotropic hormone ${ }^{[31]}$ in NIU are currently in progress.

Amidst the current global COVID-19 pandemic, one of the most common concerns we have received from patients on IMT is whether their treatment might increase the risk of worsening a COVID-19 infection if they were to contract severe acute respiratory syndrome coronavirus 2 (SARSCoV-2). Currently, there is no clear evidence to suggest that IMT for ocular diseases increases the risk for infection or complications from COVID19. Although further studies are needed, perhaps tocilizumab, which has recently been shown to reduce risk of death in patients with severe COVID-19 disease, ${ }^{[32,33]}$ can be considered as an alternative treatment option for patients with NIU who fail therapy with infliximab.

\section{Financial Support and Sponsorship}

DLH and BHP have no relevant funding disclosures. QDN and his employer, Stanford University, have received research funding from Genentech, Gilead, Regeneron, and Santen, among others.

\section{REFERENCES}

1. Uludag G PJ, Onghangseng NL, Halim MS, Hassan $M$, Doan HL, Chea S, Xiang J, Akhavanrezayat A, Do DV, Sepah YJ, Nguyen QD: Posterior Segment Manifestations in Patients with HLA-B27-Associated Uveitis. Association for Research in Vision and Ophthalmology (ARVO) Abstract A0503.

2. Campbell JP, Leder HA, Sepah YJ, Gan T, Dunn $J P$, Hatef $E$, et al. Wide-field retinal imaging in the management of noninfectious posterior uveitis. Am J Ophthalmol 2012;154:908-911.e2.

3. Leder HA, Campbell JP, Sepah YJ, Gan T, Dunn JP, Hatef E, et al. Ultra-wide-field retinal imaging in the management of non-infectious retinal vasculitis. $J$ Ophthalmic Inflamm Infect 2013;3:30.

4. Braakenburg AM, de Valk HW, de Boer J, Rothova A. Human leukocyte antigen-B27-associated uveitis: long-term follow-up and gender differences. $A m \mathrm{~J}$ Ophthalmol 2008;145:472-479.

5. Power WJ, Rodriguez A, Pedroza-Seres M, Foster CS. Outcomes in anterior uveitis associated 
with the HLA-B27 haplotype. Ophthalmology 1998;105:1646-1651.

6. Bajwa A, Maleki A, Payal AR, Fandiño A, Padrón MIM, Walsh M, Foster CS. Efficacy and Safety of Infliximab in HLA-B27- associated Ocular Inflammation Refractory or Intolerant to Conventional Immunomodulatory Therapy. J Ophthalmic Vis Res 2020;15:2-11.

7. Rathinam SR, Gonzales JA, Thundikandy R, Kanakath A, Murugan SB, Vedhanayaki R, et al. Effect of corticosteroid-sparing treatment with mycophenolate mofetil vs methotrexate on inflammation in patients with uveitis: a randomized clinical trial. JAMA 2019;322:936-945.

8. Markomichelakis $\mathrm{N}$, Delicha $\mathrm{E}$, Masselos $\mathrm{S}$, Fragiadaki K, Kaklamanis P, Sfikakis PP. A single infliximab infusion vs corticosteroids for acute panuveitis attacks in Behcet's disease: a comparative 4-week study. Rheumatology 2011;50:593-597.

9. Suhler EB, Smith JR, Giles TR, Lauer AK, Wertheim MS, Kurz DE, et al. Infliximab therapy for refractory uveitis: 2-year results of a prospective trial. Arch Ophthalmol 2009;127:819-822.

10. Markomichelakis N, Delicha E, Masselos S, Sfikakis PP. Intravitreal infliximab for sight-threatening relapsing uveitis in Behcet disease: a pilot study in 15 patients. Am J Ophthalmol 2012;154:534-541.e1.

11. Sfikakis PP, Kaklamanis PH, Elezoglou A, Katsilambros N, Theodossiadis PG, Papaefthimiou S, et al. Infliximab for recurrent, sight-threatening ocular inflammation in Adamantiades-Behcet disease. Ann Int Med 2004;140:404-406.

12. Miraldi Utz V, Bulas S, Lopper S, Fenchel M, Sa T, Mehta M, et al. Effectiveness of long-term infliximab use and impact of treatment adherence on disease control in refractory, non-infectious pediatric uveitis. Pediatr Rheumatol 2019;17:79.

13. Sfikakis PP, Theodossiadis PG, Katsiari CG, Kaklamanis P, Markomichelakis NN: Effect of infliximab on sight-threatening panuveitis in Behcet's disease. Lancet 2001;358:295-296.

14. Ohno S, Nakamura S, Hori S, Shimakawa M, Kawashima H, Mochizuki M, et al. Efficacy, safety, and pharmacokinetics of multiple administration of infliximab in Behcet's disease with refractory uveoretinitis. J Rheumato/ 2004;31:1362-1368.

15. Okada AA, Goto $H$, Ohno S, Mochizuki M. Multicenter study of infliximab for refractory uveoretinitis in Behcet disease. Arch Ophthalmol 2012;130:592-598.

16. Richards JC, Tay-Kearney ML, Murray K, Manners P. Infliximab for juvenile idiopathic arthritis-associated uveitis. Clin Exp Ophthalmol 2005;33:461-468.
17. Rajaraman RT, Kimura $\mathrm{Y}, \mathrm{Li} \mathrm{S}$, Haines K, Chu DS. Retrospective case review of pediatric patients with uveitis treated with infliximab. Ophthalmology 2006;113:308-314.

18. Hatemi G, Christensen R, Bang D, Bodaghi B, Celik AF, Fortune F, et al. 2018 update of the EULAR recommendations for the management of Behcet's syndrome. Ann Rheum Dis 2018;77:808-818.

19. Sfikakis PP, Kaklamanis PH, Elezoglou A, Katsilambros N, Theodossiadis PG, Papaefthimiou S, et al. Infliximab for recurrent, sight-threatening ocular inflammation in Adamantiades-Behçet disease. Ann Int Med 2004;140:404-406.

20. Biester S, Deuter C, Michels H, Haefner R, Kuemmerle-Deschner J, Doycheva D, et al. Adalimumab in the therapy of uveitis in childhood. Br J Ophthalmol 2007;91:319-324.

21. Jaffe GJ, Dick AD, Brézin AP, Nguyen QD, Thorne JE, Kestelyn $P$, et al. Adalimumab in patients with active noninfectious uveitis. N Engl J Med 2016;375:932943.

22. Nguyen QD, Merrill PT, Jaffe GJ, Dick AD, Kurup SK, Sheppard J, et al. Adalimumab for prevention of uveitic flare in patients with inactive non-infectious uveitis controlled by corticosteroids (VISUAL II): a multicentre, double-masked, randomised, placebocontrolled phase 3 trial. Lancet 2016;388:1183-1192.

23. Sepah YJ, Sadiq MA, Chu DS, Dacey M, Gallemore $\mathrm{R}$, Dayani P, et al. Primary (month-6) outcomes of the stop-uveitis study: evaluating the safety, tolerability, and efficacy of tocilizumab in patients with noninfectious uveitis. Am J Ophthalmol 2017;183:71-80.

24. Heissigerova J, Callanan D, de Smet MD, Srivastava SK, Karkanova M, Garcia-Garcia O, et al. Efficacy and safety of sarilumab for the treatment of posterior segment noninfectious uveitis (SARILNIU): the phase 2 SATURN study. Ophthalmology 2019;126:428-437.

25. Ibrahim MA, Sepah YJ, Watters A, Bittencourt M, Vigil EM, Do DV, et al. One-year outcomes of the SAVE study: sirolimus as a therapeutic approach for uveitis. Trans/ Vis Sci Technol 2015;4:4.

26. Nguyen QD, Merrill PT, Clark WL, Banker AS, Fardeau C, Franco P, et al. Intravitreal sirolimus for noninfectious uveitis: a phase III sirolimus study assessing double-masked uveitis treatment (SAKURA). Ophthalmology 2016;123:2413-2423.

27. Nguyen QD, Merrill PT, Sepah YJ, Ibrahim MA, Banker A, Leonardi A, et al. Intravitreal sirolimus for the treatment of noninfectious uveitis: evolution through preclinical and clinical studies. Ophthalmology 2018;125:1984-1993. 
28. Merrill PT, Clark WL, Banker AS, Fardeau C, Franco $P$, LeHoang P, et al. Efficacy and safety of intravitreal sirolimus for noninfectious uveitis of the posterior segment: results from the sirolimus study assessing double-masked uveitis treatment (SAKURA) program. Ophthalmology 2020;27:P1405-P1415.

29. Kenawy N, Cleary G, Mewar D, Beare N, Chandna A, Pearce I. Abatacept: a potential therapy in refractory cases of juvenile idiopathic arthritis-associated uveitis. Graefes Arch Clin Exp Ophthalmol 2011;249:297-300.

30. Marrani E, Paganelli V, de Libero C, Cimaz R, Simonini G. Long-term efficacy of abatacept in pediatric patients with idiopathic uveitis: a case series. Graefes Arch Clin Exp Ophthalmol 2015;253:1813-1816.

Correspondence to:

Quan Dong Nguyen, MD, MS. Spencer Center for Vision Research, Byers Eye Institute at Stanford University 2452 Watson Court Suite 200, Palo Alto, CA 94303, USA.

E-mail: ndquan@stanford.edu

\section{Access this article online}

Website: https://knepublishing.com/index.php/JOVR

DOI: $10.18502 / j o v r . v 15 i 4.7777$
31. Agarwal A, Hassan M, Sepah YJ, Do DV, Nguyen QD. Subcutaneous repository corticotropin gel for non-infectious panuveitis: reappraisal of an old pharmacologic agent. Am J Ophthalmol Case Rep 2016;4:78-82.

32. Cortegiani A, Ippolito M, Greco M, Granone V, Protti A, Gregoretti C, Giarratano A, Einav S, Cecconi M: Rationale and evidence on the use of tocilizumab in COVID-19: a systematic review. Pulmonology 2020; [Epub ahead of print].

33. Toniati P, Piva S, Cattalini M, Garrafa E, Regola F, Castelli F, et al. Tocilizumab for the treatment of severe COVID-19 pneumonia with hyperinflammatory syndrome and acute respiratory failure: a single center study of 100 patients in Brescia, Italy. Autoimmun Rev 2020;19:102568.

This is an open access journal, and articles are distributed under the terms of the Creative Commons Attribution-NonCommercial-ShareAlike 4.0 License, which allows others to remix, tweak, and build upon the work non-commercially, as long as appropriate credit is given and the new creations are licensed under the identical terms.

How to cite this article: Hien DL, Pham BH, Nguyen QD. How Do We Manage HLA-B27-associated Ocular Inflammation Refractory or Intolerant to Conventional Immunomodulatory Therapy?. J Ophthalmic Vis Res 2020;15:442-445. 